\title{
Mineral Content in Capsicum Pepper Landraces: Effect of the Genotype and the Ripening Stage
}

\author{
Ana M. RIBES-MOYA ${ }^{1)}$, Leandro PEREIRA ${ }^{1)}$, Carla GUIJARRO-REAL ${ }^{1)}$; M. Dolores RAIGON ${ }^{2}$, Ana M. \\ FITA $^{11}$, Adrián RODRÍGUEZ-BURRUEZO ${ }^{1 *}$ \\ 1)Institute COMAV and ${ }^{2)}$ Department of Chemistry, ${ }^{(1,2)}$ Universitat Politècnica de València, Camino de \\ Vera s/n, 46022, Valencia, Spain. \\ ${ }^{*}$ Corresponding author, e-mail: adrodbur@doctor.upv.es
}

Bulletin UASVM Horticulture 71(2) / 2014

Print ISSN 1843-5254, Electronic ISSN 1843-5394

DOI:10.15835/buasvmcn-hort:10679

\begin{abstract}
Capsicum peppers are one of the most important vegetables and a plethora of cultivars can be found within common pepper, C. annuum. In this regard, Spain is a center of diversity for this crop. Many studies on bioactive compounds have been done in peppers, although very little is known about their mineral content. In the present work fruits from a comprehensive collection of Capsicum accessions, mostly C. annиum landraces, were grown in open field in Valencia (Spain) and evaluated at both unripe and fully ripe stages for their content in several minerals: P, K, Ca, Mg and Fe. The effects of the genotype, fruit ripening stage, and the genotypexripening stage were studied. A wide genotypic diversity was found for minerals. Thus, the difference between the lowest and highest genotype means was about twice in both ripening stages for $\mathrm{P}, \mathrm{Ca}$, and $\mathrm{Mg}$ and for $\mathrm{K}$ in fully ripe fruits. Finally, Fe levels were $0.7-3.1 \%$ in unripe fruits and $1.07-5.1 \%$ in fully ripe fruits. Our results indicate that C. annuum fruits are a good source of $\mathrm{K}$, particularly when unripe. With very few exceptions, $\mathrm{P}, \mathrm{K}$ and particularly Ca decreased on average and in most genotypes with the ripening process. By contrast, Mg showed a strong genotypexstage interaction. Here we found a wide diversity among $C$. annuum genotypes for the content in most minerals, particularly in P, Ca and Mg, as well as high levels of K. Moreover, unripe fruits usually show higher levels of these minerals than fully ripe fruits.
\end{abstract}

Keywords: Capsicum peppers, fruit composition, mineral content, ripening stage, variability

Introduction. Fruits from the cultivated forms of genus Capsicum are one of the most popular vegetables in the world and there is a plethora of dishes, pastes, and sauces in which peppers contribute with their particular color and flavor (DeWitt and Bosland, 2009). Their use, not only as vegetable, but also as a spice, as well as their introduction and adaptation to different regions and human preferences, has contributed to such diversity of uses (DeWitt and Bosland, 2009). Furthermore, Capsicum peppers can be utilized at both mature and immature stages. Among the species domesticated by humans, $C$. annuum L. or common pepper is the most popular, genetically diverse, and economically important species, and their cultivars are grown worldwide (Nuez et al., 2003; DeWitt and Bosland, 2009). After the discovery of America, Spain was the entrance to Europe for many American species and, consequently, became an important center of diversity for this crop.

Moreover, in the last decades, consumers' preferences have evolved towards more healthy products, and many vegetables can provide high levels of minerals, vitamins, and/or antioxidants. At the nutritional level, Capsicum annuum fruits are known for their content in many bioactive compounds with antioxidant activity like ascorbic acid or phenolics (Rodríguez-Burruezo et al., 2009). However, very little is known about their mineral content and the effect of genotype and ripening stage.

Aims and objectives. In the present contribution we studied the levels in $\mathrm{P}, \mathrm{K}, \mathrm{Ca}$, $\mathrm{Mg}$ and Fe of different Capsicum peppers at the unripe and fully ripe stages. The objectives were: 
Tab. 1. P, K, Ca, Mg and Fe level (mean, mg/100 g DM) in unripe and fully ripe Capsicum fruits.

\begin{tabular}{|c|c|c|c|c|c|c|c|c|c|c|}
\hline \multirow{2}{*}{ Accession } & \multicolumn{2}{|c|}{$\mathrm{P}$} & \multicolumn{2}{|c|}{$\mathrm{K}$} & \multicolumn{2}{|c|}{$\mathrm{Ca}$} & \multicolumn{2}{|c|}{$\mathrm{Mg}$} & \multicolumn{2}{|c|}{$\mathrm{Fe}$} \\
\hline & Unripe & Ripe & Unripe & Ripe & Unripe & Ripe & Unripe & Ripe & Unripe & Ripe \\
\hline \multicolumn{11}{|l|}{ C. annuum } \\
\hline Ancho $101 \mathrm{~B}$ & 287 & 269 & 2353 & 1832 & 34 & 13 & 155 & 112 & 0.98 & 1.65 \\
\hline Bierzo I.G.P. & 304 & 207 & 2776 & 2045 & 31 & 16 & 201 & 200 & 1.70 & 5.12 \\
\hline Bola D.O.P. & 306 & 166 & 2732 & 2755 & 34 & 10 & 189 & 145 & 1.51 & 1.98 \\
\hline Chile de Árbol & 281 & 158 & 3929 & 2503 & 25 & 17 & 206 & 238 & 0.78 & 2.54 \\
\hline Chile Serrano & 193 & 166 & 3270 & 2274 & 29 & 16 & 139 & 220 & 0.73 & 1.54 \\
\hline Guacilla Pulla & 312 & 278 & 3392 & 2895 & 29 & 14 & 123 & 260 & 1.48 & 1.51 \\
\hline Jalapeño & 251 & 158 & 2319 & 1802 & 34 & 16 & 153 & 102 & 1.13 & 1.07 \\
\hline Najerano & 358 & 286 & 3332 & 1509 & 35 & 14 & 177 & 245 & 3.14 & 2.10 \\
\hline Numex Conquistador & 250 & 200 & 2491 & 1917 & 29 & 16 & 182 & 204 & 1.30 & 1.32 \\
\hline Pasilla Bajío & 347 & 247 & 2317 & 1767 & 32 & 15 & 239 & 166 & 2.00 & 1.47 \\
\hline Pimiento Valenciano & 269 & 305 & 3298 & 2359 & 61 & 17 & 250 & 272 & 1.29 & 3.55 \\
\hline Piquillo & 285 & 283 & 2402 & 2335 & 21 & 14 & 183 & 181 & 1.06 & 1.91 \\
\hline Ros Mallorquí & 351 & 277 & 3091 & 2366 & 34 & 15 & 241 & 242 & 2.43 & 1.81 \\
\hline \multicolumn{11}{|l|}{ C. frutescens } \\
\hline Ají Chirere & 259 & 206 & 2773 & 1702 & 38 & 21 & 250 & 147 & 1.27 & 9.83 \\
\hline \multicolumn{11}{|l|}{ C. baccatum } \\
\hline $37 \mathrm{R}$ & 190 & 162 & 2993 & 2258 & 30 & 19 & 210 & 274 & 1.04 & 2.05 \\
\hline MEAN & 283 & 225 & 2898 & 2155 & 33 & 16 & 193 & 201 & 1.46 & 2.63 \\
\hline
\end{tabular}

i) to study the effects of the genotype, ripening stage and their interaction (GxS) in the content of minerals and ii) to identify those cultivars with high content in one or more minerals at each ripening stage.

Materials and methods. Fifteen Capsicum accessions, mostly $C$. annuum, including several Spanish landraces, were grown in open field in Valencia (Spain) during the 2013 spring-summer season. Both unripe and fully ripe fruits were evaluated for their content in several minerals: $\mathrm{P}, \mathrm{K}, \mathrm{Ca}, \mathrm{Mg}$ and $\mathrm{Fe}$, according to MAPA methods (1994), based on five replicates (samples) per accession/fruit stage combination. Each sample was prepared with fruits from two different plants. Therefore, ten plants per accession and ripening stage were sampled.

Results and discussion. A wide genotypic diversity was found for minerals. Thus, genotypic differences were about two-fold between the lowest and the highest means in both stages for $\mathrm{P}$ (unripe: $190-351 \mathrm{mg} / 100 \mathrm{~g}$; fully ripe: 158-305), Ca (25-61; 10-21), and Mg (123-250; 102-274) and for K in fully ripe fruits (1509-2755) (Table 1). Genotypic differences were still higher in $\mathrm{Fe}$, with means comprised between 0.7 and $3.1 \%$ and 1.1$5.1 \%$ in unripe and fully ripe fruits, respectively (Table 1). On average and in most accessions, peppers showed higher levels in $\mathrm{P}, \mathrm{K}$, and $\mathrm{Ca}$ when unripe, although the contrary was true for Fe (Table 1). Finally, a remarkable GxS interaction was found for $\mathrm{Mg}$, and some accessions showed higher levels at the unripe stage, while others showed the contrary. With very few exceptions, P, K and particularly Ca decreased on average and in most genotypes with the ripening process. By contrast, $\mathrm{Mg}$ and $\mathrm{Fe}$ showed a strong genotypexstage interaction.

Conclusion. Our results suggest that there are ample opportunities to select high-mineral content genotypes among Capsicum peppers, particularly when unripe, and also that $C$. annuum genotypes are a rich source of $\mathrm{K}(>2000 \mathrm{mg} / 100$ g d.m.).

Acknowledgement: work financed by INIA (RTA2010-00038-C03-03), FEDER funds.

\section{REFERENCES}

1. DeWitt D, Bosland PW (2009). The complete chile pepper book. Timber Press, Portland USA

2. MAPA. 1994. Métodos Oficiales Análisis. Vol. II. Ministerio Agricultura, Pesca Alimentación, Madrid, Spain.

3. Nuez F, Gil-Ortega R, Costa J (2003). El cultivo de pimientos, chiles y ajíes. MundiPrensa, Madrid, Spain.

4. Rodríguez-Burruezo A, Prohens J, Raigón MD, Nuez F (2009). Variation for bioactive compounds in ají (Capsicum baccatum L.) and rocoto (C. pubescens R. \& P.) and implications for breeding. Euphytica 170:169-181. 